WORKING PAPER - NO. 2020-62

\title{
US Unemployment Insurance Replacement Rates During the Pandemic
}

Peter Ganong, Pascal Noel, and Joseph Vavra

AUGUST 2020

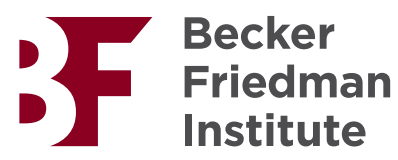




\title{
US Unemployment Insurance Replacement Rates During the Pandemic
}

\author{
Peter Ganong, Pascal Noel, and Joseph Vavra*
}

August 24, 2020

\begin{abstract}
We use micro data on earnings together with the details of each state's unemployment insurance (UI) system to compute the distribution of UI benefits after the uniform $\$ 600$ Federal Pandemic Unemployment Compensation (FPUC) supplement implemented by the CARES Act. We find that between April and July 2020, $76 \%$ of workers eligible for regular Unemployment Compensation have statutory replacement rates above $100 \%$, meaning that they are eligible for benefits which exceed lost wages. The median statutory replacement rate is $145 \%$. We also compute comprehensive replacement rates, which account for employer provided non-wage compensation and differential tax treatment of labor income and UI. $69 \%$ of UI-eligible unemployed have comprehensive replacement rates above $100 \%$ and the median comprehensive replacement rate is $134 \%$. The presence of the FPUC has important implications for the incidence of the recession and reverses income patterns which would have otherwise arisen across income levels, occupations, and industries.
\end{abstract}

*ganong@uchicago.edu, pascal.noel@chicagobooth.edu, joseph.vavra@chicagobooth.edu We thank Gabe Chodorow-Reich, Michele Evermore, Jason Faberman, Nathaniel Hendren, Bruce Meyer, Marokey Sawo, Wayne Vroman and Stephen Wandner for helpful feedback, and Peter Robertson, Roshan Mahanth and Isaac Liu for excellent research assistance. We thank the Becker Friedman Institute at the University of Chicago for financial support. Replication code is available at https://github.com/ganong-noel/ui_rep_rate. 


\section{Introduction}

The Coronavirus Aid, Relief, and Economic Security Act (CARES) Act substantially expanded Unemployment Insurance (UI) in order to help workers losing jobs as a result of the Covid-19 pandemic. One provision of the Act creates an additional $\$ 600$ weekly benefit known as the Federal Pandemic Unemployment Compensation (FPUC). The size of the payment - \$600 - was designed to replace 100 percent of the mean U.S. wage when combined with mean state UI benefits. In this paper, we use micro data on earnings together with the details of each state's UI system under the CARES Act to compute the distribution of UI benefit amounts from April to July 2020.

We use these estimates to calculate the distribution of lost earnings replaced by unemployment benefits and how these replacement rates vary across occupations, industries and states. We focus primarily on measuring benefits owed to those who are eligible for regular Unemployment Compensation (henceforth referred to for brevity as the "unemployed"). ${ }^{1}$ Our baseline statutory replacement rate compares an unemployed worker's UI benefit to their lost wage earnings. However, we also compute a comprehensive replacement rate, which instead compares unemployment benefits to a broader measure of lost earnings which includes nonwage compensation like employer-provided health insurance and accounts for the differential tax treatment of labor income and UI.

As designed, the ratio of mean unemployment benefits to mean pre-tax wages under CARES is roughly $100 \%$. However, this masks substantial heterogeneity. We find that $76 \%$ of unemployed workers have a statutory replacement rate above $100 \% .^{2}$ That means that three in four unemployed workers are eligible for benefits which exceed their lost wages. The median statutory replacement rate is $145 \%$. $69 \%$ of unemployed workers have comprehensive replacement rates above $100 \%$ and so qualify for unemployment benefits which exceed total post-payroll tax wages and non-wage compensation. The median comprehensive replacement rate is $134 \%$.

These conclusions arise because the CARES Act sends a fixed $\$ 600$ supplement to unemployed workers who have very different pre-job loss earnings: $\$ 600$ is a larger percentage of pre-job loss earnings for low than for high earners. The CARES Act implemented a fixed supplement to all workers in part because it was viewed as infeasible to implement policies which depended on individual earnings. Since the $\$ 600$ UI supplement was targeted to generate $100 \%$ earnings replacement based on mean earnings, this $\$ 600$ supplement tends to imply greater than $100 \%$ earnings replacement for those with less than mean earnings. Furthermore, these high replacement rates for below-mean workers are amplified by the fact that the distribution of earnings is skewed: median earnings are less than mean earnings. This means that the typical unemployed worker has below-mean prior earnings and thus above-mean replacement rates. This implies that most workers have replacement rates above $100 \%$.

There is sizable variation in the effects of the CARES Act across occupations, industries and states. These in turn have important distributional consequences. For example, the median laid-off retail worker can collect $166 \%$ of their prior wage in UI, while grocery workers who remain employed are not receiving any automatic pay increases. Janitors working at businesses that remain open do not necessarily receive any hazard pay, while the median unemployed janitor who worked at businesses that shut down can collect

\footnotetext{
${ }^{1}$ We show that including those eligible for benefits under Pandemic Unemployment Assistance Program (PUA) modestly increases estimated replacement rates.

${ }^{2}$ In a prior draft of the paper, we estimated this share was $68 \%$. As discussed below, the difference arises because job losses in the pandemic have been skewed towards low-income workers who have higher replacement rates. The prior draft used the distribution of pre-job loss earnings from before the pandemic, while we now estimate replacement rates based on the distribution of pre-job loss earnings for those actually unemployed during the pandemic, since this data has now become available.
} 
$167 \%$ of their prior wage.

Our results focus primarily on calculating replacement rates conditional on being unemployed. However, unemployment rates vary dramatically by income and across different occupations and industries. For this reason, it is interesting to explore how UI supplements affected the distributional incidence of the pandemic across these groups. In particular, we compute how the income of a typical worker in different groups changes on average over the pandemic given that groups' wages, unemployment rate and unemployment benefits, but without conditioning on an individual worker's ex-post employment status. ${ }^{3}$ That is, we compute how the expansion of UI changed the expected income of a typical worker in a group during the pandemic.

We find that the presence of the FPUC reverses group-level income patterns which would otherwise arise as a result of the pandemic. For example, unemployment rose more for retail workers than for teachers during the pandemic. Under normal UI benefits, this greater increase in unemployment would lead the expected income of retail workers to decline relative to that of teachers. However, under the $\$ 600$ FPUC, these patterns reverse: expected income for the median retail worker actually rose, both in absolute terms and relative to the median teacher.

We also find similar reversals when sorting by pre-job loss earnings: workers with low earnings prior to the pandemic were much more likely to become unemployed during the pandemic. Low earning workers would have thus faced greater declines in expected income than high earning workers under normal UI, which replaces only a fraction of lost earnings. Under the $\$ 600$ FPUC, low-earning workers instead had greater ex-ante increases in expected income than high-earning workers.

These results show that UI benefits are crucial for understanding the distributional incidence of the pandemic and that unlike in normal recessions, groups with dramatic declines in labor income during the pandemic do not necessarily have commensurate declines in overall cash flow once UI benefits are included. That is, while unemployment variation across different groups like industries or states is a good proxy for labor income variation, it is not a good proxy for total income variation during the early months of this recession. This is in turn important for understanding overall spending patterns during this recession (Bachas et al. 2020). It also implies that research designs which rely on employment shift-shares as instruments for overall income must be interpreted with care during this recession.

After documenting these basic patterns, we briefly explore how various alternative UI supplement policies like those currently debated in Congress or announced by the Presidential Memorandum on August 8, 2020 would alter the distribution of replacement rates. However, our paper is a purely descriptive analysis of the effects of UI supplements on household income, and we take no stand on optimal policy. Furthermore, it is important to note what our paper does and does not show. Our paper shows that the $\$ 600$ supplement to UI through the FPUC led to high replacement rates and thus substantially boosted the income of the unemployed during the initial stages of the pandemic. Our paper does not provide any evidence on the consequences of this income support for other important outcomes of interest like spending or labor supply. However, concurrent research has begun to explore these implications.

Farrell et al. (2020) finds that the marginal propensity to consume out of the $\$ 600$ FPUC supplements was large, and argues that these supplements thus helped insure households against material hardship and stimulated aggregate demand. Casado et al. (2020) reaches similar conclusions using regional data. Indeed, Bachas et al. (2020) shows that the spending of low income households recovered most rapidly after the start of government stimulus and income support programs, even though low income households lost more

\footnotetext{
${ }^{3}$ Most calculations in our paper focus on the distribution of benefits for which the unemployed are eligible. However, processing delays mean many unemployed workers face benefits delays (Bitler, Hoynes, and Schanzenbach 2020). This analysis, which describes the implications for the overall distribution of income, takes into account these payment delays.
} 
labor income during the recession (Cajner et al. 2020a). These papers imply that the liquidity provision and income support provided by the FPUC likely played an important positive role in stimulating aggregate spending.

At the same time, very high replacement rates might be expected to deter labor supply and depress employment as the economy recovers. However, this is an empirical question, and so far early research has not found evidence that high replacement rates are deterring aggregate employment (see e.g. Altonji et al. 2020, Bartik et al. 2020, and Dube 2020). Limited labor supply effects in the presence of unemployment benefits which exceed wages could arise from the fact that the FPUC was temporary, with an initial expiration four months after the CARES Act was signed into law. Models of the labor market which include relevant search frictions predict that workers should compare the flow value of unemployment to the expected present discounted value of a potential employment match. Just because a worker can temporarily earn more on unemployment than by working does not necessarily mean that they will turn down an offer of employment. Petrosky-Nadeau (2020) and Boar and Mongey (2020) estimate that even with the $\$ 600$ supplement, most unemployed would accept an offer at their previous wages.

Furthermore, the effects of individual labor supply decisions on aggregate employment may depend on the overall tightness of the labor market. Disincentive effects of high unemployment benefits on labor supply are likely to matter less in a slack labor market with many more available workers than available jobs than in a healthy labor market with more jobs than available workers. Marinescu, Skandalis, and Zhao (2020) show that vacancies fell much more than applications during the pandemic, which suggests that it should be easier rather than harder for employers to hire during the recession.

Nevertheless, Barrero, Bloom, and Davis (2020) show that even in the peak period of job losses, there were many businesses with both gross and net hiring. For example, as waiters were laid off, there was substantial hiring in food delivery, and Amazon increased employment in response to increased demand for online shopping. While we do not know of any current empirical estimates, high UI benefits could deter this type of beneficial labor reallocation. Furthermore, these types of labor supply disincentives from high replacement rates are likely to grow in importance as the public health threat diminishes and businesses again look to hire. This is one argument in favor of tying the level of unemployment benefit supplements to current economic conditions.

The remainder of the paper proceeds as follows. Section 2 discusses our data and methodology. Section 3 shows the implications of FPUC for replacement rates over the earnings distribution. Section 4 explores incidence across occupations and states. Section 5 explores various robustness checks.

\section{Methodology and Data}

While the basic intuition for why a fixed supplement can generate high replacement rates is simple, a careful accounting of the distribution of replacement rates requires combining data on the prior earnings of the unemployed with the the state-specific eligibility and benefit rules. ${ }^{4}$ Our analysis of these interactions relies on two key ingredients: a simulator for unemployment benefits, and micro data with earnings and labor force status from the Current Population Survey (CPS).

\footnotetext{
${ }^{4}$ Gonshorowski and Greszler (2020) and Anderson and Levine (2020) note that a fixed dollar increase in UI benefits leads to replacement rates above $100 \%$ for lower income workers. Our analysis quantifies the prevalence of this phenomenon using micro data.
} 


\section{Figure 1: Unemployment Benefits versus Earnings}

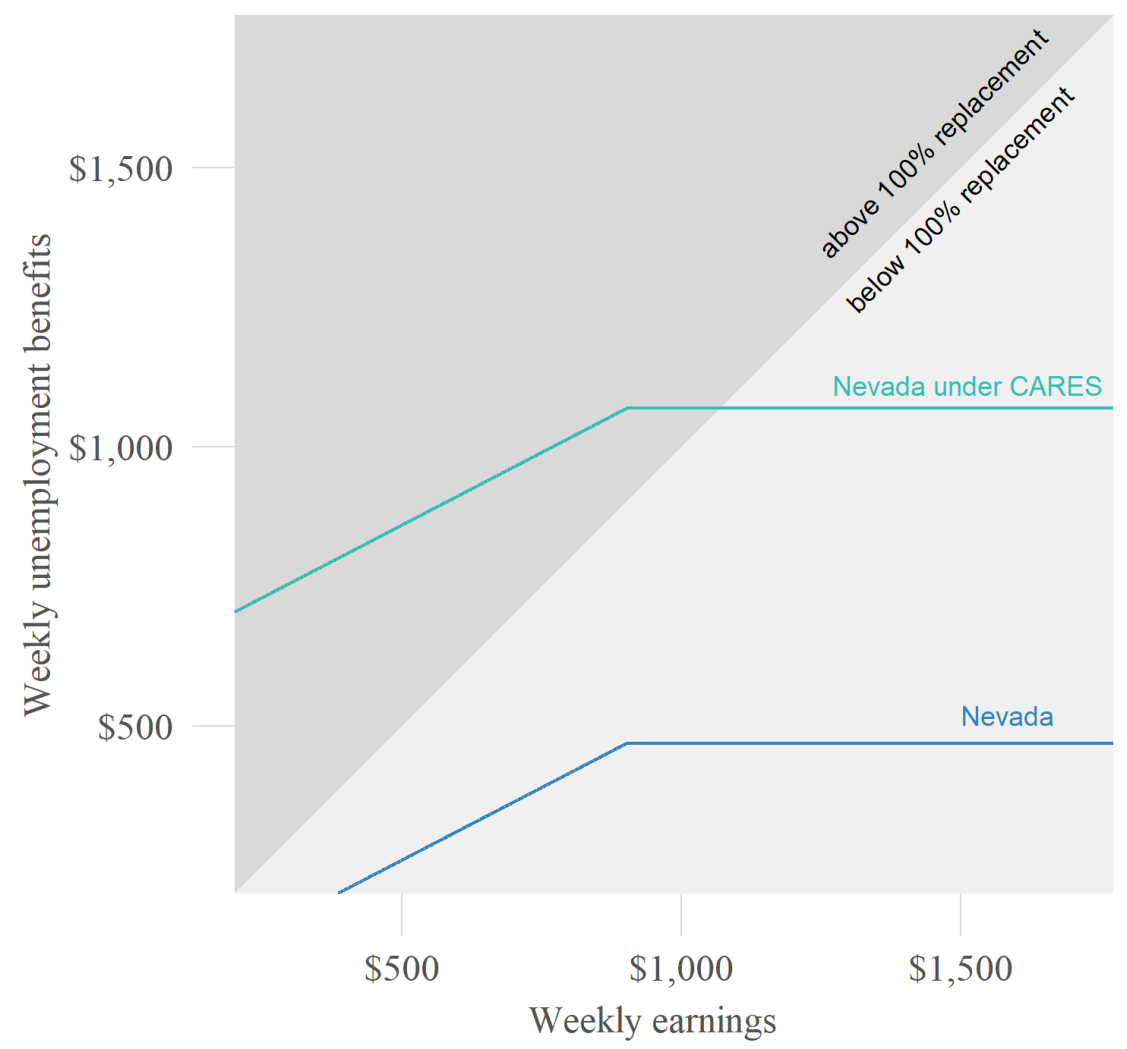

Notes: This figure shows unemployment benefits for various values of weekly earnings in Nevada both in normal times and under the CARES Act, which adds a $\$ 600$ supplement to weekly benefits. We choose Nevada for this illustrative example because it has average UI benefit levels in the middle of the national distribution.

\subsection{UI Benefit Rules}

For the first ingredient, we construct estimates of the unemployment benefits received according to the "Significant Provisions of State Unemployment Insurance Laws" document produced in January 2020 (U.S. Department of Labor (2020)). This document outlines the eligibility criteria and benefit schedules by state. Where states have multiple ways to qualify for unemployment benefits, we allow only the primary listed way in the document. We calculate benefit amounts for a single unemployed person with no dependents. We do not consider eligibility through alternative base periods. To find benefit amounts under the CARES Act we add $\$ 600$ to benefit amounts from January 2020 .

UI systems prior to the CARES Act typically provide benefits which are a fixed fraction of workers' previous earnings, up to some cap. For example, Figure 1 shows the benefit schedule for Nevada both before and after the CARES Act. We show results for Nevada since it has average UI benefit levels in the middle of the national distribution, but qualitatively similar schedules apply in other states.

The blue line shows the level of UI payments as a function of prior earnings. Nevada has a replacement rate of $52 \%$ of prior weekly earnings and a cap of $\$ 469$, so benefits increase by 52 cents for each dollar of prior weekly earnings, until reaching a max benefit of $\$ 469$ for workers with earnings above $\$ 902$. This leads to a sharp kink at $\$ 902$ and implies that replacement rates are below $52 \%$ for workers with higher earnings. 
The turquoise line shows the new benefit schedule under the CARES Act, which simply shifts the previous schedule vertically by $\$ 600$. We also divide the benefit schedule along a 45 degree line where the level of benefits would exactly equal the level of previous earnings. Benefit values falling in the dark region above the 45 degree line are larger than earnings and imply replacement rates above $100 \%$. Benefit values falling in the light region below the 45 degree line imply replacement rates below $100 \%$. This figure shows that for workers with low earnings, UI benefits can potentially far exceed lost earnings. Under the CARES Act, replacement rates thus vary over the entire earnings distribution, so calculating the distribution of replacement rates requires information on the distribution of earnings.

\subsection{Unemployment and Earnings Data}

We estimate the earnings history of the unemployed by combining data from the 2019 Annual Social and Economic Supplement (ASEC) of the CPS with information on the distribution of unemployment in the basic monthly CPS from April-July, 2020 (Ruggles et al. 2020). ${ }^{5}$ The ASEC survey was administered in February, March, and April 2019 and asks about labor supply in calendar year 2018. ${ }^{6}$ States calculate UI benefits on the basis of a worker's quarterly earnings history, which is not available in the ASEC. We simulate quarterly earnings from the ASEC in two steps. First, we compute average weekly wage as the ratio of annual earnings to weeks worked last year. Second, we assume that each worker was working in the final week of 2018, and that they worked consecutively at the same average weekly earnings for the total number of weeks they reported working in 2018. This procedure makes their highest quarter earnings synonymous with their most recent quarter earnings.

Throughout our analysis we restrict the sample to labor force participants who are US citizens, have average hourly earnings above the federal minimum wage $(\$ 7.25)$, and have sufficient simulated quarterly earnings history to be eligible for regular Unemployment Compensation in their state of residence. ${ }^{7}$ There are 64,901 workers that meet these three criteria.

Although the ASEC was run prior to the pandemic, our analysis captures the composition of likely UI claimants during the pandemic on several observable dimensions by using a companion data set built from the basic monthly CPS. Specifically, we study the probability of unemployment amongst CPS labor force participants in April, May, June, and July 2020 who also responded to a survey question about weekly earnings as part of the Merged Outgoing Rotation Group (MORG) in 2019. There are 61,378 workers that meet these criteria. We identify workers who are likely to meet the eligibility criteria to claim UI because they have a duration of unemployment of less than 26 weeks and were laid off from their prior jobs, to capture restrictions against voluntary quitters receiving UI. We refer to this group as the "unemployed" for brevity. ${ }^{8}$

We use a reweighting procedure to make the pre-pandemic ASEC sample match the unemployed during

\footnotetext{
${ }^{5}$ Ideally, we would use micro data on workers who actually claim UI during the pandemic, but we are unaware of any publicly-available source of such data.

${ }^{6}$ The CPS ASEC administered in spring 2020, which captures labor supply in calendar year 2019, will not be available until later in 2020, after this draft was written.

${ }^{7}$ The ASEC explicitly asks workers about income from tips and we include tipped workers in our main sample in order to be as representative as possible. However, there is some evidence that tips are under-reported in the CPS. Whether this generates bias in our estimates depends on the nature of under-reporting of tips. If a tipped worker reports zero income from tips then our benefit simulator will likely judge them to be ineligible, and they are excluded from the analysis sample. However, if a worker reports only some tips, then our method overstates their replacement rate. To address this concern, we report a robustness check in Section 5.2 which is conservative in that it drops all workers in occupations with a high prevalence of tips.

${ }^{8}$ This is a subset of the group that is used to compute the official unemployment rate. The official unemployment rate also includes people entering the labor market after a period of not working and people who quit their prior job.
} 
the pandemic on observable characteristics. Specifically, we run the following logit regression

$$
\left.\operatorname{logit}_{\left(P\left(\text { Unemployed }_{i}\right)\right.}\right)=\text { Wage Decile }_{i}+\text { State }_{i}+\text { Occupation }_{i}+\text { Industry }_{i}+\epsilon_{i}
$$

in the basic monthly CPS sample, where WageDecile $_{i}$ is a fixed effect for decile of 2019 weekly earnings, State $_{i}$ is a state dummy, Occupation ${ }_{i}$ is a fixed effect for two digit occupation, and Industry $y_{i}$ is a fixed effect for two digit industry. We then use the estimated coefficients from this regression to predict an individual's probability of unemployment during the pandemic in the ASEC sample that we use for actual analysis of earnings. The analysis in this paper weights each worker in the ASEC by the product of their person weight and their probability of unemployment during the pandemic. Because unemployment during the pandemic is concentrated amongst those with low income, and the federal supplement is a fixed amount, this reweighting procedure modestly increases estimated replacement rates relative to using the raw ASEC data.

Figure 2 panel (a) shows the distribution of pre-job loss weekly earnings among likely UI eligible households from April to July 2020 under this procedure. ${ }^{9}$ There are two key features of the earnings distribution. First, there is substantial variance in earnings across workers. Second, the distribution is right-skewed, so that the mean earnings level of $\$ 886$ during the pandemic is well above the median earnings level of $\$ 630$ for the same time period. Concretely, this implies that most workers have earnings below the mean. Furthermore, the mean earnings of unemployed workers during the pandemic of $\$ 886$ is itself lower than mean earnings of unemployed workers prior to the pandemic (in 2019) of $\$ 1,010$. This is because unemployment during this recession is concentrated among low earners, as shown in panel (b). This is important because the $\$ 600$ payment under the CARES Act targeted an average replacement rate of $100 \%$, but used data on mean earnings of the unemployed prior to the pandemic.

\subsection{Validation of Methodology Using Benchmarks from Administrative Data}

Combining the ingredients in Sections 2.1 and 2.2 allows us to estimate the distribution of unemployment benefits. To assess the validity of our methodology, we compare our estimates to data on average benefits and pre-job loss earnings of actual UI claimants as reported by the Department of Labor. For April to July 2020 , estimated average weekly benefits without FPUC in the US are $\$ 321$, compared to actual average benefits of $\$ 308$. Figure A-1 panel (a) shows that our estimates closely track actual variation in UI benefits at the state level during the pandemic. Panels (b) and (c) of the same figure show that our estimates also track actual variation in UI benefit levels and pre-job loss earnings for the 2019 ASEC. The similarity of estimated average benefits and earnings to benchmarks from administrative data bolsters the credibility of our methods.

\subsection{Replacement Rate Definitions}

In this paper we report results for two alternative definitions of the "replacement rate", which is the ratio of benefits to earnings. The first definition, which we refer to as the statutory replacement rate, is the ratio of pre-tax benefits to pre-tax earnings. State UI policies are formulated in terms of statutory replacement rates, and this is the definition that has been used in the prior academic literature. The second definition, which we refer to as the comprehensive replacement rate, incorporates two of the most important factors

\footnotetext{
${ }^{9}$ It is useful to note that a modest share of workers have pre-job loss weekly earnings below $\$ 290$ (the product of the federal minimum wage and 40 hours per week) despite the fact that we restrict analysis to those with average hourly earnings above the federal minimum wage; this pattern reflects workers who had part-time jobs prior to unemployment.
} 


\section{Figure 2: Distribution of Pre-Job Loss Earnings and Unemployment}

\section{(a) Earnings Distribution of the Unemployed}

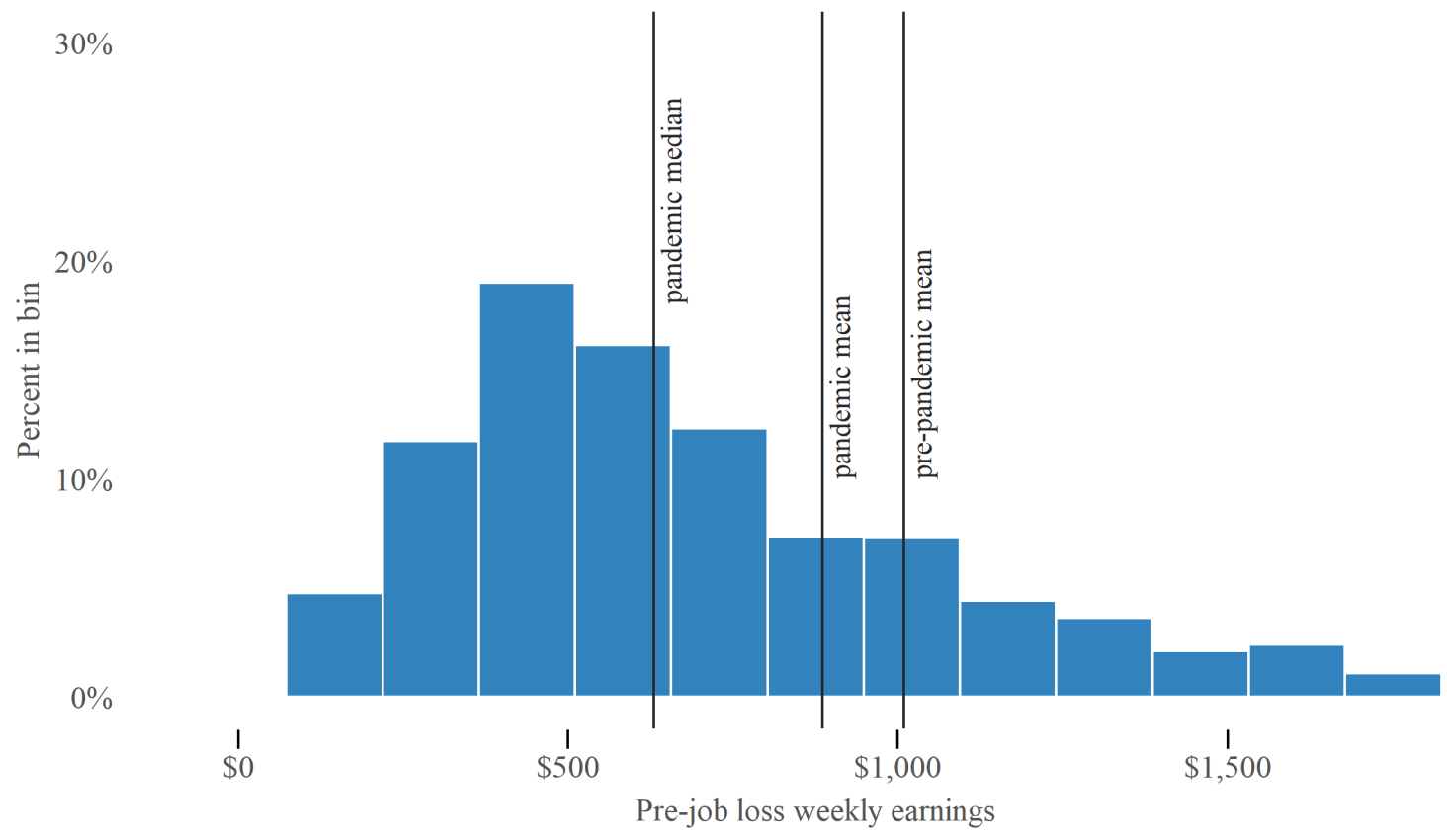

(b) Unemployment Rate by Pre-Job Loss Earnings

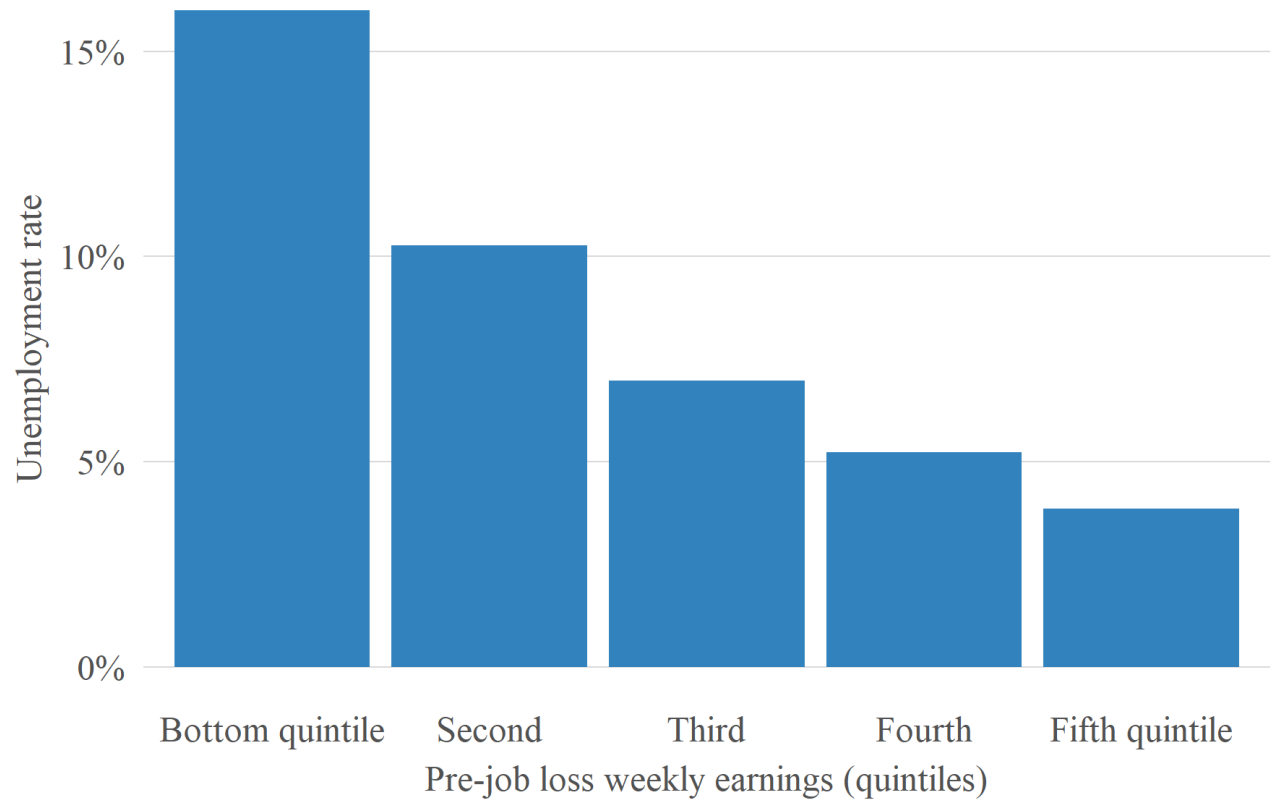

Notes: We analyze employment and pre-job loss weekly earnings in April-July 2020 of workers who are eligible for regular unemployment compensation. Panel (a) shows the distribution of weekly earnings. Panel (b) shows the unemployment rate by quintiles of the earnings distribution (quintiles are defined without conditioning on unemployment and so capture the earnings distribution of all workers). 
that affect the pecuniary benefits from work: payroll taxes (which lower the value of work) and non-wage compensation (which raises the value of work).

Unfortunately, no individual-level survey captures all non-wage compensation. We impute non-wage compensation at the individual worker level by rescaling employer-provided health insurance contributions in the CPS ASEC by the ratio of total non-wage compensation to health insurance benefits in the BLS Employer Costs for Employee Compensation report. ${ }^{10}$ We then add these imputed benefits at the individual worker-level to their labor earnings to impute worker-level total compensation.

Most of the paper reports results in terms of statutory replacement rates, which do not require this imputation procedure and align with how state UI agencies traditionally set the level of UI benefits, but in Section 5 we report results in terms of comprehensive replacement rates. We also explore additional robustness checks which exclude tipped workers and which try to account for the presence of the Pandemic Unemployment Assistance (PUA program) and its interaction with lost self-employment earnings.

\section{$3 \quad$ Estimated Replacement Rates}

Combining information on the distribution of prior earnings by the unemployed in each state with that state's benefit schedule allows us to estimate the level of replacement rates across the earnings distribution of the unemployed. Figure 3 panel (a) shows these results. The horizontal line denotes a replacement rate of $100 \%$. The facts that 1) most workers have earnings below the mean and 2) mean earnings of unemployed workers during the pandemic are themselves lower than the mean earnings prior to the pandemic (that were targeted with the $\$ 600$ supplement) imply substantial replacement rates for the typical unemployed worker during the pandemic. Under the CARES Act, $76 \%$ of workers have replacement rates above $100 \%{ }^{11}$ The median replacement rate is $145 \%$ and a typical worker in the bottom two deciles of the income distribution has a replacement rate of more than $200 \%$.

Figure 3 panel (b) shows how UI benefits under the CARES Act compare to earnings for unemployed workers in various occupations. ${ }^{12}$ This figure again shows substantial variation: lower-wage jobs effectively have much higher replacement rates than higher wage jobs, often substantially above $100 \%$. This has important distributional and equity implications, even for workers in the same occupation. For example, unemployed janitors who worked at businesses which are closed can get UI benefits equal to $167 \%$ of their prior earnings, while janitors who continue to work at increased health risk in businesses deemed "essential" have no guarantees of any hazard pay or increased earnings. ${ }^{13}$

Appendix Figure A-3 and corresponding Appendix Table A-1 shows how typical replacement rates under CARES vary across states. While there is substantial variation across states, the median replacement rate in all states is well above $100 \%$. The intuition for the distribution of replacement rates across states is similar

\footnotetext{
${ }^{10}$ Specifically, we multiply employer-provided health benefits by $(7.95-2.16) / 2.60=2.23$ to estimate total benefits. This scaling factor arises from information on employer benefit costs from Bureau of Labor Statistics (2020). We focus on private industry workers where unemployment is currently concentrated and exclude employer taxes (legally required benefits). This analysis uses the 2017 ASEC, because the employer-provided health benefits variable is unavailable in the 2019 ASEC.

${ }^{11}$ In a prior draft, we estimated that $68 \%$ of unemployed workers had benefits that exceed wages. That draft did not reweight to match the distribution of characteristics of the unemployed during the pandemic since this data was unavailable at the time of writing. Our current estimate of $76 \%$ is slightly below estimates by the CBO produced after our initial draft: https://www.cbo.gov/system/files/2020-06/56387-CBO-Grassley-Letter.pdf. This modest difference likely in part reflects that they compare UI benefits to "potential wages" which they assume will be depressed rather than to prior wages.

${ }^{12}$ Figure A-2 shows similar results by industry.

${ }^{13}$ The large estimated replacement rates for food service workers raise the concern that we may be under-measuring tips in occupations where tips are common and therefore may lead us to overstate replacement rates. However, Section 5 shows that dropping occupations where tips are common has little effect on our conclusions.
} 
Figure 3: Statutory Replacement Rates

(a) Across the Earnings Distribution

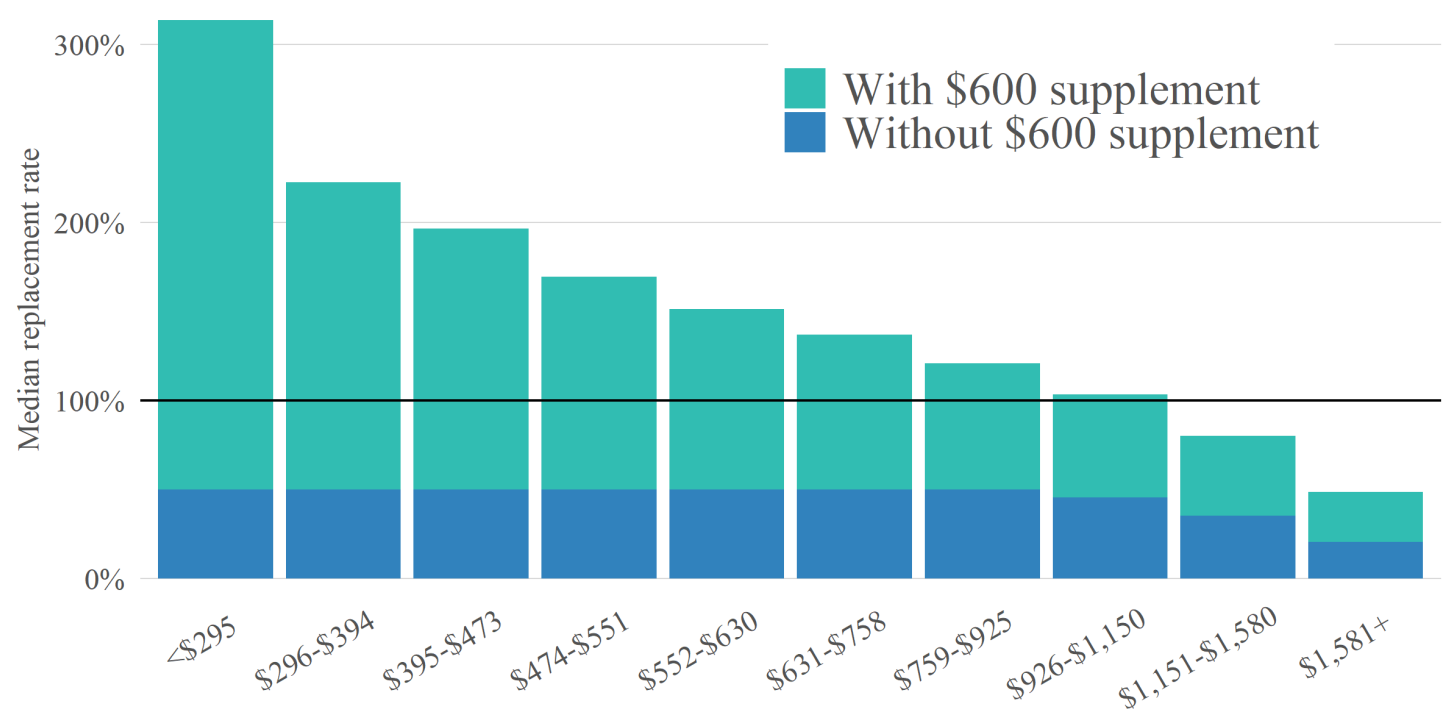

Pre-job loss weekly earnings (deciles)

(b) Common Occupations

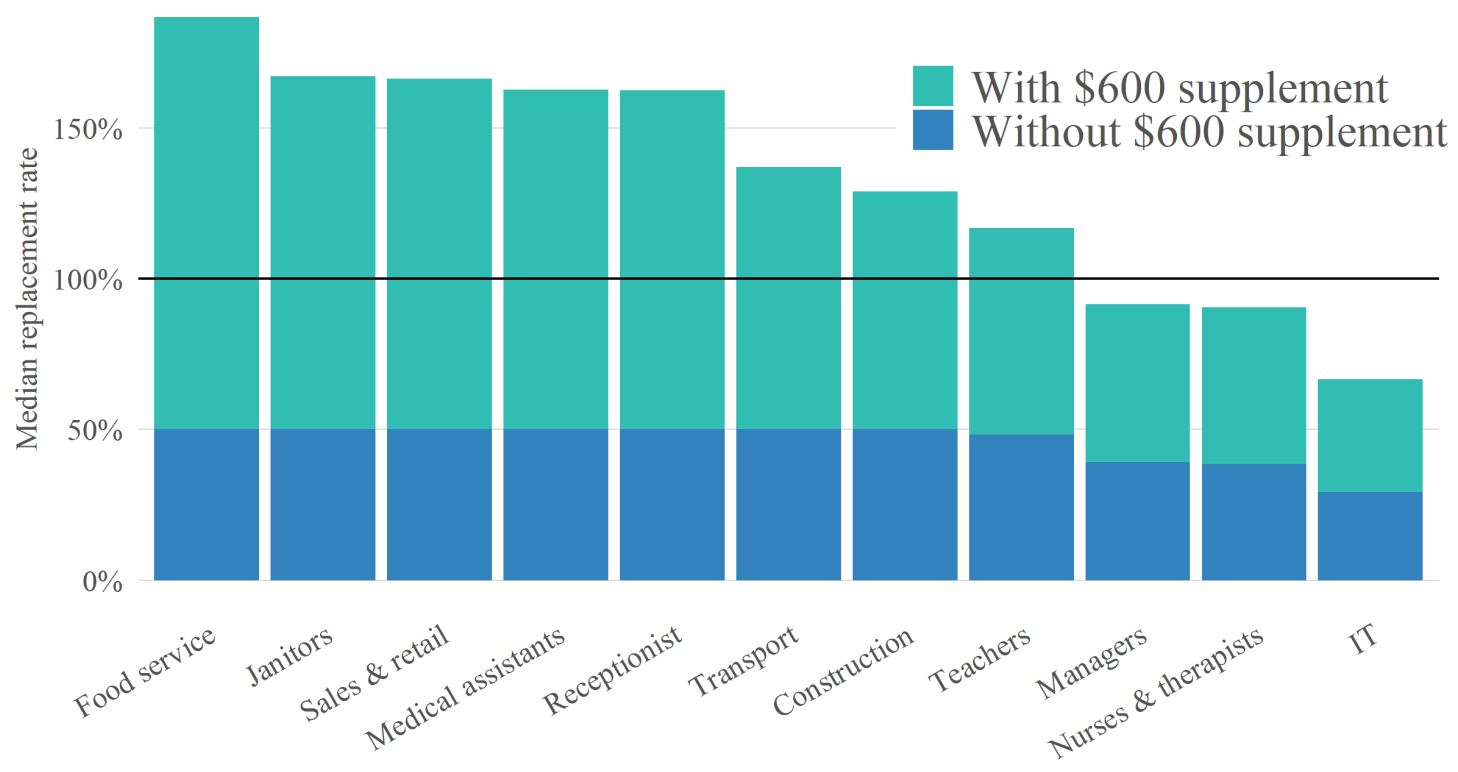

Notes: This figure shows the fraction of pre-tax earnings that are replaced by unemployment benefits (statutory replacement rates). In panel (a) the bins correspond to deciles of the pre-job loss weekly earnings distribution for the unemployed and we report replacement rates for the median unemployed worker in each bin. Panel (b) shows the median fraction of pre-tax earnings that are replaced by unemployment benefits (statutory replacement rates) for workers in eleven of the most common occupations. The horizontal line in both panels shows a replacement rate of $100 \%$, which is where benefits are equal to earnings. The estimates are statistically precise; Table 2 provides standard errors on the distribution of replacement rates and the standard error for the occupation-level estimates is always less than 4.3 percentage points. 
to the intuition for the distribution across the earnings distribution discussed above: when a fixed $\$ 600$ supplement is added to everyone's benefits, states with the lowest pre-job loss earnings of the unemployed will have the highest replacement rates. We note that this is similar to, but not the same as, more commonly reported statistics of typical earnings for all workers in a state. Oklahoma has the highest replacement rate. The median UI eligible worker in Oklahoma has a replacement rate of $165 \%$. Georgia and New Mexico are the next highest, with median replacement rates of $163 \%$ and $162 \%$. Arizona has the lowest median replacement rate. The median UI eligible worker in Arizona can receive benefits equal to $119 \%$ of lost earnings. Massachusetts and New York are the next lowest, with median replacement rates of $135 \%$ in both states.

Our estimated replacement rates are similar to actual replacement rates calculated using administrative data from California. We estimate a median replacement rate in California of $142.6 \%$ (standard error 3.2 percentage points) while the California Policy Lab finds a replacement rate of $136.3 \% .{ }^{14}$ Further, we find a median replacement rate for Californians who are unemployed in the "Leisure and Hospitality" industry of $172 \%$ vs. $173 \%$ in the California administrative claims data. The similarity of our estimates, which require a benefit calculator and combining evidence from multiple CPS surveys, to statistics for the one state where administrative data are available bolsters the credibility of our findings.

\section{Incidence and Implications for Overall Income Distribution}

Our results thus far calculate the replacement rates that workers are eligible for, conditional on being unemployed and claiming UI benefits. However, unemployment rates vary dramatically across the income distribution and for different sectors of the economy, so it is interesting to compute the effect of UI supplements on the overall distribution of income for workers in different occupations and industries. The specific question we ask is: from an ex ante perspective, how might a worker in different sectors expect their income to change from the pandemic without conditioning on employment status?

To capture heterogeneity in how incomes have changed during the pandemic, we combine information on pre-job loss earnings, unemployment rates in May 2019 and May 2020, and imputed UI benefits with and without the $\$ 600$ FPUC supplement. It is important to note that not all unemployed workers received benefits in May 2020 because of delays in processing UI claims as well as eligibility rules (e.g. undocumented workers are not eligible). We estimate recipiency rates as the ratio of actual benefits paid out to the benefits that would have been paid out if every unemployed worker had received benefits; this yields an estimated UI recipiency rate of $77 \%$ in May 2020. ${ }^{15}$ Table 1 shows how expected income (labor income if employed or UI benefits times the probability of benefit recipiency if unemployed) for a worker with the median wage in different groups changed as a result of the group-specific increase in unemployment during the pandemic. ${ }^{16}$

\footnotetext{
${ }^{14}$ https://www.capolicylab.org/wp-content/uploads/2020/07/July-2nd-Analysis-of-UI-Claims-in-California-During-theCOVID-19-Pandemic.pdf

${ }^{15}$ The numerator in this calculation is benefits paid out in May 2020 for regular unemployment compensation from Department of Labor Form 5159. To calculate the denominator, which is the budgetary cost if every unemployed worker had received benefits, we multiply the average benefit in our analysis sample by the number of unemployed within each group. This calculation assumes an aggregate unemployment rate of $16.3 \%$, which is the May 2020 unemployment rate after correcting for misclassification error. The unemployed are distributed between groups in Table 1 (and, in the case of the occupation analysis, occupations not listed) according to the estimated unemployment rates reported in the table. Note that the numerator in this calculation uses only regular unemployment compensation, while the denominator includes both people eligible for regular unemployment compensation as well as those eligible for PUA (but ineligible for regular unemployment compensation). Thus, this calculation is a lower bound on the PUA-inclusive UI recipiency rate. See Cajner et al. (2020b) for a careful reconciliation of UI claims and unemployment during the pandemic.

${ }^{16}$ Cajner et al. (2020a) provides evidence that wage changes conditional on employment have been modest during the recession, and we do not have 2020 ASEC data, so we assume that earnings conditional on employment in May 2020 are the same as in
} 


\section{Table 1: Changes in Income Distribution}

(a) By Pre-Job Loss Earnings

\begin{tabular}{|c|c|c|c|c|c|}
\hline \multirow[b]{2}{*}{ Earnings quintile } & \multirow[b]{2}{*}{ Weekly earnings } & \multicolumn{2}{|c|}{ Unemployment rate } & \multicolumn{2}{|c|}{ Median change in income } \\
\hline & & 2019 & 2020 & without FPUC & with FPUC \\
\hline Bottom quintile $(<\$ 490)$ & $\$ 372$ & $2.6 \%$ & $19.9 \%$ & $-9.3 \%$ & $19.5 \%$ \\
\hline Second quintile (\$491-\$760) & $\$ 592$ & $1.5 \%$ & $12.8 \%$ & $-6.1 \%$ & $5.0 \%$ \\
\hline Third quintile $(\$ 761-\$ 1,060)$ & $\$ 886$ & $1.5 \%$ & $8.0 \%$ & $-3.4 \%$ & $1.1 \%$ \\
\hline Fourth quintile $(\$ 1,061-\$ 1,630)$ & $\$ 1,280$ & $0.9 \%$ & $6.2 \%$ & $-3.5 \%$ & $-1.0 \%$ \\
\hline Top quintile $(\$ 1,631+)$ & $\$ 2,323$ & $0.8 \%$ & $3.8 \%$ & $-2.5 \%$ & $-1.6 \%$ \\
\hline
\end{tabular}

(b) By Occupation

\begin{tabular}{lrrrrrr}
\hline & & \multicolumn{2}{c}{ Unemployment rate } & & \multicolumn{2}{c}{ Median change in income } \\
Occupation & Weekly earnings & 2019 & 2020 & & without FPUC & with FPUC \\
\hline Food service & $\$ 491$ & $6.0 \%$ & $36.8 \%$ & & $-18.5 \%$ & $18.9 \%$ \\
Janitors & $\$ 591$ & $4.3 \%$ & $15.2 \%$ & & $-5.9 \%$ & $6.6 \%$ \\
Medical assistants & $\$ 591$ & $3.2 \%$ & $12.7 \%$ & $-5.2 \%$ & $5.2 \%$ \\
Receptionist & $\$ 591$ & $7.4 \%$ & $19.4 \%$ & $-6.1 \%$ & $9.8 \%$ \\
Sales \& retail & $\$ 689$ & $4.2 \%$ & $17.9 \%$ & $-7.7 \%$ & $4.7 \%$ \\
Transport & $\$ 827$ & $2.5 \%$ & $17.0 \%$ & $-8.5 \%$ & $1.0 \%$ \\
Construction & $\$ 853$ & $5.3 \%$ & $16.3 \%$ & $-6.0 \%$ & $3.2 \%$ \\
Teachers & $\$ 984$ & $1.3 \%$ & $10.2 \%$ & $-5.6 \%$ & $-0.8 \%$ \\
Nurses \& therapists & $\$ 1,280$ & $1.6 \%$ & $3.4 \%$ & $-1.1 \%$ & $0.2 \%$ \\
Managers & $\$ 1,477$ & $1.4 \%$ & & $5.0 \%$ & $-2.6 \%$ & $-1.0 \%$ \\
IT & $\$ 1,713$ & $1.2 \%$ & $3.1 \%$ & $-1.3 \%$ & $-0.5 \%$ \\
\hline
\end{tabular}

This table shows how the US income distribution changed from the increase in unemployment from May 2019 to May 2020 and the $\$ 600$ supplement to unemployment benefits known as Federal Pandemic Unemployment Compensation (FPUC). Weekly earnings is the median of weekly earnings for employed workers in that earnings quintile or occupation in the 2019 ASEC. The earnings for employed worker $i$ are the same in 2019 and 2020: $w_{i, 2020}=w_{i, 2019}$. Expected income for worker $i$ in quintile or occupation $j$ is $E_{i, t}=w_{i, t} \times\left(1-u_{j(i), t}\right)+u_{j(i), t} \times$ benefit $t_{i, t} . u_{j(i), t}$ is the unemployment rate in group $j$ in period $t$ and benefit $t_{i, t}$ is an estimate of the benefit that worker $i$ is eligible for times an estimate of the recipiency rate of unemployment benefits for unemployed workers in period $t$. The final two columns then compute for each quintile or occupation: $\operatorname{Median}_{j}\left(E_{i, 2020} / E_{i, 2019}\right)$ with and without the $\$ 600$ FPUC. In panel (a), quintiles are defined without conditioning on unemployment and so capture the earnings distribution of all workers. The unemployment rate in panel (a) differs from Figure 2 panel (b) because that panel captures April through July 2020, while this table examines only May 2020.

In Appendix Table A-2 we show similar results by industry. ${ }^{17}$ The median change without FPUC shows the percentage change in income during the pandemic absent the FPUC supplement, while the median change with FPUC shows our estimate of how income changed under the enhanced UI system.

We find that the presence of the FPUC reverses income patterns by income level and sector which would otherwise arise as a result of the pandemic. For example, Table 1 panel (a) shows that under normal UI benefits, expected income for median workers in the bottom quintile would have fallen by $9.3 \%$, but with the $\$ 600$ FPUC it rose by $19.5 \%$. In a similar vein, panel (b) shows that unemployment rose more for retail workers than for teachers during the pandemic. Under normal UI benefits, this greater increase in unemployment leads the expected income for the median retail worker to decline by $7.7 \%$ while the income

\footnotetext{
May 2019.

${ }^{17}$ In addition, we have also explored results which compute expected changes in income for which workers are eligible rather than expected changes in the actual income they receive; that is assuming recipiency rates of $100 \%$. Conclusions are similar.
} 
of the median teacher falls by $5.6 \%$. Under the FPUC, these patterns reverse: rather than falling, expected income for retail workers actually rises by $4.7 \%$ during the pandemic, and teachers' expected income is essentially unchanged. Looking at incidence by industry in Table A-2 shows that the presence of the FPUC undoes what would otherwise be massive income declines for workers in "Leisure and Hospitality", "Other services", and "Wholesale and retail trade" industries. These results show that UI benefits are crucial for understanding the distributional incidence of the pandemic and that sectors with the most dramatic declines in labor income do not necessarily have the most dramatic declines in income inclusive of UI transfers.

\section{Robustness}

Our paper's key estimates are of the distribution of statutory replacement rates, which we find are 103\% at the 25 th percentile, $145 \%$ at the 50 th percentile, and $195 \%$ at the 75 th percentile, together with the $76 \%$ share of the unemployed eligible for benefits above pre-job loss earnings. In this section, we explore the robustness of our results on a number of important dimensions. Table 2 reports all of these results.

Table 2: Distribution of Replacement Rates Robustness

\begin{tabular}{lrrrr}
\hline & \multicolumn{4}{c}{ Percentile } \\
\cline { 2 - 4 } & 25 th & 50 th & 75 th & Share over 1 \\
\hline Main estimate & $103 \%(1.7)$ & $145 \%(1.6)$ & $195 \%(3.1)$ & $76 \%(0.7)$ \\
\hline Comprehensive replacement rate & & & & \\
$\quad$ Include non-wage compensation & $85 \%(0.9)$ & $125 \%(1.2)$ & $184 \%(2.5)$ & $65 \%(0.7)$ \\
$\quad$ Account for payroll tax & $111 \%(1.8)$ & $157 \%(1.7)$ & $211 \%(3.4)$ & $80 \%(0.6)$ \\
$\quad$ Account for payroll tax and include non-wage compensation & $91 \%(1.0)$ & $134 \%(1.3)$ & $200 \%(2.7)$ & $69 \%(0.7)$ \\
\hline Statutory replacement rate & & & & \\
$\quad$ Include self-employment income & $102 \%(1.6)$ & $144 \%(1.5)$ & $195 \%(3.1)$ & $76 \%(0.7)$ \\
$\quad$ Drop tipped occupations & $94 \%(1.4)$ & $135 \%(1.4)$ & $177 \%(1.8)$ & $72 \%(0.8)$ \\
$\quad$ Include PUA recipients & $105 \%(1.7)$ & $149 \%(1.6)$ & $202 \%(3.1)$ & $77 \%(0.7)$ \\
\hline
\end{tabular}

This table shows how the distribution of replacement rates changes under alternative assumptions. The top row shows our main estimate of statutory replacement rates. Standard errors in percentage points are in parentheses. For example, the median replacement rate is $145 \%$ with a standard error of 1.4 percentage points. The first three rows of robustness checks show the effects of incorporating non-wage compensation and payroll tax. The third row is our preferred comprehensive measure of replacement rates. The fourth row drops tipped workers, for whom the CPS may understate earnings, thereby leading to an over-estimate of replacement rates. The fifth row includes PUA recipients. The sixth row includes self-employment income in the measure of earnings.

\subsection{Sampling Uncertainty}

While we concentrate on point estimates throughout our analysis in the prior sections, our main replacement rate estimates are statistically precise, with standard errors ranging from 0.7 to 3.1 percentage points. These standard errors capture sampling uncertainty from both the ASEC and the MORG. To account for sampling uncertainty in the ASEC we use the replicate weights calculated by the Census. These replicate weights ensure the standard errors take into account the complex sampling structure of the ASEC. Replicate weights are unavailable for the MORG from Ruggles et al. (2020), so to account for sampling uncertainty in the MORG, we instead bootstrap using 300 bootstrap replicates. While the standard errors for more disaggregated results like state-level replacement rates are modestly larger than those for national results, they remain fairly precisely estimated. 


\subsection{Employer Provided Non-Wage Compensation}

While results thus far focus on statutory replacement rates, many workers receive non-wage compensation like employer-provided health benefits, retirement contributions and paid leave. For workers with any non-wage compensation, statutory replacement rates which compare UI benefits to lost wages will exceed replacement rates which compare UI benefits to total compensation. The "Include non-Wage compensation" row shows that resulting replacement rates remain quite high. The median replacement rate is $125 \%$ and $65 \%$ of UI eligible workers have replacement rates above $100 \%{ }^{18}$

\subsection{Tax Treatment of UI Benefits}

We next explore the role of differential tax treatment of UI benefits and labor income. Labor income up to $\$ 137,700$ is subject to a payroll tax of $7.65 \%$ while unemployment benefits are not considered earned income and so are exempt from this payroll tax. ${ }^{19}$ This means that after-tax replacement rates are higher than the pre-tax statutory rates that our paper focuses on. Accounting for the fact that UI benefits are not subject to payroll taxes raises the median after-tax replacement rate from $145 \%$ to $157 \%{ }^{20}$ The share of unemployed with after-tax replacement rates above $100 \%$ is $80 \%$.

Combining the adjustments for non-wage compensation and payroll taxes gives us our preferred comprehensive measure of replacement rates in Table 2. $69 \%$ of workers have comprehensive replacement rate above $100 \%$ and the median value of this replacement rate is $134 \%$. Thus, most regular UI eligible workers have after-tax UI benefits which exceed their total lost labor compensation.

\subsection{Tipped Workers}

We next explore the role of tips. The high replacement rates for food service workers stand out in Figure 3b. Workers in these occupations are often paid tips. While the CPS survey prompts workers to include tips in their earnings, there is some concern that these may be under-reported. If workers understate their total pay, then we may overstate their replacement rates. To address this concern, we recompute our main statistics after excluding workers in occupations where tips and commissions are important. ${ }^{21}$ Table 2 shows that replacement rates after excluding tipped occupations are reduced slightly but remain quite high. This shows that our conclusions are not driven by under counting income for workers who typically earn tips.

\subsection{Pandemic Unemployment Assistance (PUA)}

Our main results focus on replacement rates for recipients of regular Unemployment Compensation (UC). We focus on UC because there is much better data on the program's administration. However, PUA expanded benefit eligibility to a much larger set of workers who do not meet the normal state monetary eligibility threshold for UC. To explore the role of PUA for our results, we assume that job losers in the CPS not

\footnotetext{
${ }^{18}$ Accounting for non-wage compensation does lower replacement rates, but it does not change the conclusion that the vast majority of workers have replacement rates above $100 \%$. This stands in contrast to an interpretation of results in Sawo and Evermore (2020) based on industry averages. However, as we noted above, skewed earnings distributions make it difficult to interpret calculations based on averages. We have replicated their finding that most unemployed workers are in industries where the industry average UI benefit is below the industry average total compensation. Despite this industry-level pattern, Table 2 shows that most individual unemployed workers indeed have UI benefits which exceed their individual total compensation.

${ }^{19}$ The Executive Order issued on August 8, 2020 makes the ongoing payroll tax treatment of labor income uncertain, but our estimates focus on the period prior to FPUC expiration which precedes this order.

${ }^{20} 1.57 / 1.45=1 /(1-.0765)$

${ }^{21}$ See our online replication materials for the classification of tipped occupations. We use an expansive definition of occupations with tips and commissions that includes $35 \%$ of workers.
} 
meeting the UC monetary eligibility threshold instead qualify for PUA. This methodology captures people with limited prior earnings who are eligible for PUA, but does not capture self-employed people who are eligible for PUA. We further assume that these workers then receive UI payments equal to one-half of the state average UI benefit amount in addition to the $\$ 600$ FPUC. ${ }^{22}$ Table 2 shows that including PUA recipients modestly increases statutory replacement rates.

\subsection{Self-Employment Income and Program Interactions}

We next explore interactions between PUA and UC. These interactions mean that some workers who qualify for UC may have replacement rates measured in terms of wage earnings which are larger than their replacement rates measured under a broader notion of labor earnings. In particular, the PUA program expanded UI eligibility to cover many workers with self-employment income. However, PUA is only available for workers who do not qualify for UC. This means that workers with enough wage income to qualify for UC must collect UC benefits even if they have self-employment income which exceeds wage income. For these workers, measuring replacement rates in terms of wage earnings will overstate overall replacement rates.

To explore this issue, for each individual we add wage income to self-employment income in the CPS to get a broader measure of earnings. We continue to restrict the sample to UC eligible workers who qualify for benefits based on their wage earnings, but then compute replacement rates as the ratio of benefits to wages plus self-employment income. Table 5 shows that including self-employment for these workers has a negligible effect on replacement rates. This is because there are very few workers who qualify for UC based on wage income but also have sizable self-employment income. ${ }^{23}$

\section{$6 \quad$ Policy Options}

In the final part of this note, we evaluate the distributional consequences of supplementary fixed payments of various sizes. Although the CARES Act used a $\$ 600$ supplement, Congress has debated a range of values for continuing supplements. In Figure 4, we show how the distribution of replacement rates varies with fixed payments. The diagonal black line shows the share of workers with replacement rates above $100 \%$. The figure demonstrates that it is quite difficult to achieve high replacement rates for most workers without also having replacement rates over $100 \%$ for many workers. Figure A- 4 shows an alternative visualization of the same information using bar charts.

\section{Conclusion}

The expanded UI system enacted under CARES implied high replacement rates well over 100\% for most workers. High replacement rates can provide crucial liquidity necessary for households to smooth consumption during this unprecedented period of economic dislocation. Notably, a fixed dollar supplement provides the largest comparative benefit to the lowest income workers, who might otherwise be especially hurt by this recession. At the same time, replacement rates over $100 \%$ may hamper efficient labor reallocation during

\footnotetext{
${ }^{22}$ This corresponds to the minimum PUA payout amount. Preliminary data suggests that most PUA recipients are receiving this minimum payment. However, accounting for PUA recipients who receive benefits above this minimum would further increase implied replacement rates and so amplify our conclusions.

${ }^{23}$ In the CPS only $0.17 \%(104 / 62204)$ of workers with sufficient wage earnings to be eligible for UC have self-employment income which exceeds wage income.
} 
Figure 4: Distribution of Replacement Rates for Alternative UI Policies

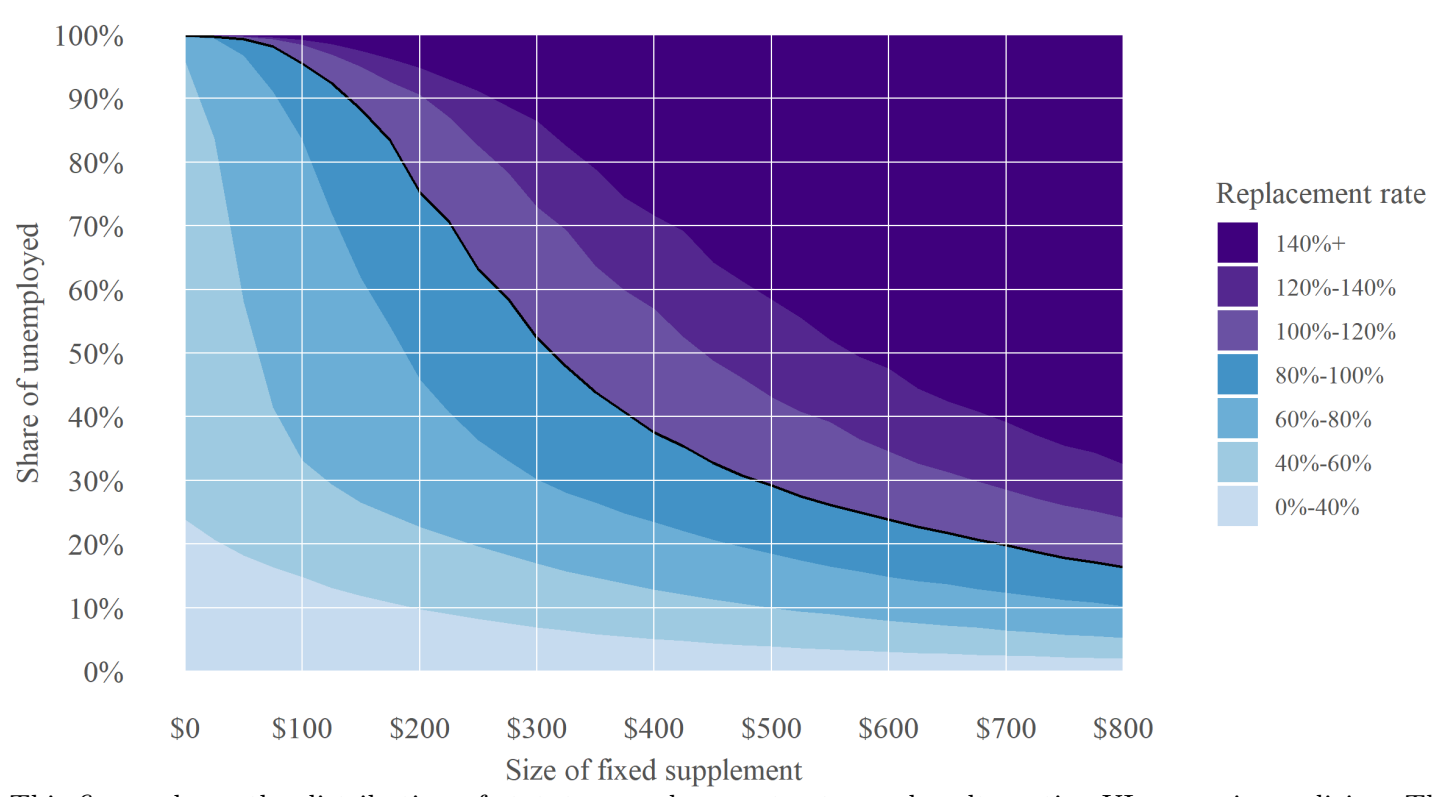

Notes: This figure shows the distribution of statutory replacement rates under alternative UI expansion policies. The size of the supplement under the CARES Act was $\$ 600$. The black line shows a replacement rate of $100 \%$.

an eventual economic recovery. That is, expanded UI induces potential trade-offs between consumption smoothing and moral hazard.

Finally, we note that high replacement rates introduce important distributional concerns. This system essentially pays bonuses to some workers who are laid off (which might lead to advantageous increases in social distancing) but provides no additional pay for otherwise similar "essential" workers. We take no stand in this paper on the empirical size of or optimal way to balance these trade-offs, but we note that this is an area of substantial current academic and policy interest.

Overall, the $\$ 600$ supplement had important effects on the incidence of the pandemic across different sectors. It was in fact large enough to reverse sectoral income changes which would have otherwise arisen from large increases in unemployment. Our results thus show that the $\$ 600$ FPUC was central to overall income dynamics during the early parts of the pandemic.

\section{References}

Altonji, Joseph, Zara Contractor, Lucas Finamor, Ryan Haygood, Ilse Lindenlaub, Costas Meghir, Cormac O'Dea, Dana Scott, Liana Wang, and Ebonya Washington. 2020. "Employment Effects of Unemployment Insurance Generosity During the Pandemic." Tech. rep.

Anderson, Patricia and Phillip Levine. 2020. "The Unemployed and essential Low-Wage Workers After the CARES Act."." Tech. rep., ECONOFACT Note. URL https://econofact.org/ the-unemployed-and-essential-low-wage-workers-after-the-cares-act.

Bachas, Natalie, Peter Ganong, Pascal J Noel, Joseph Vavra, Arlene Wong, Diana Farrell, and Fiona E Greig. 2020. "Initial Impacts of the Pandemic on Consumer Behavior: Evidence from Linked Income, Spending, and Savings Data." Brookings Papers on Economic Activity . 
Barrero, Jose Maria, Nicholas Bloom, and Steven Davis. 2020. "Covid-19 is Also a Reallocation Shock." Brookings Papers on Economic Activity .

Bartik, Alexander W, Marianne Bertrand, Feng Lin, Jesse Rothstein, and Matt Unrath. 2020. "Measuring the labor market at the onset of the COVID-19 crisis." Working Paper 27613, National Bureau of Economic Research.

Bitler, Marianne, Hilary Hoynes, and Diane Schanzenbach. 2020. "The social safety net in the wake of COVID-19." Brookings Papers on Economic Activity .

Boar, Borina and Simon Mongey. 2020. "Dynamic trade-offs and labor supply under the CARES Act." Tech. rep.

Bureau of Labor Statistics. 2020. EMPLOYER COSTS FOR EMPLOYEE COMPENSATION â USDL-201232 MARCH 2020. URL https://www.bls.gov/news.release/pdf/ecec.pdf.

Cajner, Tomaz, Leland Dod Crane, Ryan Decker, John Grigsby, Adrian Hamins-Puertolas, Erik Hurst, Christopher Johann Kurz, and Ahu Yildirmaz. 2020a. "The U.S. Labor Market During the Beginning of the Pandemic Recession." Tech. Rep. WP 2020-58, University of Chicago, Becker Friedman Institute for Economics.

Cajner, Tomaz, Andrew Figura, Brendan Price, David Ratner, and Alison Weingarden. 2020b. "Reconciling Unemployment Claims with Job Losses in the First Months of the COVID-19 Crisis." .

Casado, Miguel Garza, Britta Glennon, Julia Lane, David McQuown, Daniel Rich, and Bruce A Weinberg. 2020. "The Effect of Fiscal Stimulus: Evidence from COVID-19." Working Paper 27576, National Bureau of Economic Research.

Dube, Arindrajit. 2020. "The Impact of the Federal Pandemic Unemployment Compensation on Employment: Evidence from the Household Pulse Survey." Tech. rep.

Farrell, Diana, Peter Ganong, Fiona Greig, Max Liebeskind, Pascal Noel, and Joseph Vavra. 2020. "Consumption Effects of Unemployment Insurance During the Covid-19 Pandemic." Tech. rep., JPMorgan Chase Institute.

Gonshorowski, Drew and Rachel Greszler. 2020. "The Impact of Additional Unemployment Insurance Benefits on Employment and Economic Recovery: How the \$600-per Week Bonus Could Backfire." Tech. rep., Heritage Foundation Backgrounder 3490.

Marinescu, Ioana, Daphne Skandalis, and Daniel Zhao. 2020. "Job Search, Job Posting and Unemployment Insurance During the COVID-19 Crisis." Tech. rep.

Petrosky-Nadeau, Nicolas. 2020. "Reservation Benefits: Assessing job acceptance impacts of increased UI payments." Federal Reserve Bank of San Francisco.

Ruggles, Steven, Sarah Flood, Ronald Goeken, Josiah Grover, Erin Meyer, Jose Pacas, and Matthew Sobek. 2020. IPUMS dataset. URL https://doi.org/10.18128/D010.V10.0.

Sawo, Marokey and Michele Evermore. 2020. "Unemployed Workers and Benefit Replacement Rate: An Expanded Analysis." Tech. rep. 
U.S. Department of Labor. 2020. Significant Provisions of State Unemployment Insurance Laws. URL https://oui.doleta.gov/unemploy/content/sigpros/2020-2029/January2020.pdf. 


\section{A Appendix}

\section{Table A-1: Median Statutory Replacement Rates by State}

\begin{tabular}{llllll}
\hline & \multicolumn{2}{c}{ Replacement rate (SE) } & & \multicolumn{2}{c}{ Replacement rate (SE) } \\
\cline { 2 - 3 } \cline { 5 - 6 } State & with FPUC & Without FPUC & State & with FPUC & Without FPUC \\
\hline Alaska & $139 \%(6.1)$ & $46 \%(0.6)$ & Montana & $154 \%(3.0)$ & $52 \%(0.0)$ \\
Alabama & $148 \%(1.3)$ & $47 \%(0.7)$ & North Carolina & $152 \%(1.1)$ & $50 \%(0.0)$ \\
Arkansas & $152 \%(3.6)$ & $50 \%(0.0)$ & North Dakota & $148 \%(5.1)$ & $50 \%(0.0)$ \\
Arizona & $119 \%(5.8)$ & $34 \%(1.6)$ & Nebraska & $152 \%(6.1)$ & $50 \%(0.0)$ \\
California & $143 \%(3.2)$ & $50 \%(0.0)$ & New Hampshire & $139 \%(4.0)$ & $48 \%(1.3)$ \\
Colorado & $150 \%(5.2)$ & $60 \%(0.0)$ & New Jersey & $141 \%(6.0)$ & $60 \%(0.0)$ \\
Connecticut & $145 \%(5.1)$ & $50 \%(0.0)$ & New Mexico & $162 \%(5.2)$ & $53 \%(0.0)$ \\
Delaware & $159 \%(7.5)$ & $57 \%(0.0)$ & Nevada & $139 \%(2.3)$ & $52 \%(0.0)$ \\
Florida & $148 \%(1.0)$ & $47 \%(0.3)$ & New York & $135 \%(2.9)$ & $50 \%(0.0)$ \\
Georgia & $163 \%(1.8)$ & $62 \%(1.7)$ & Ohio & $142 \%(4.2)$ & $50 \%(0.0)$ \\
Hawaii & $149 \%(3.6)$ & $62 \%(0.0)$ & Oklahoma & $165 \%(6.9)$ & $57 \%(0.0)$ \\
Iowa & $151 \%(2.7)$ & $57 \%(0.0)$ & Oregon & $158 \%(6.6)$ & $65 \%(0.0)$ \\
Idaho & $152 \%(3.9)$ & $50 \%(0.0)$ & Pennsylvania & $147 \%(4.1)$ & $51 \%(0.0)$ \\
Illinois & $149 \%(4.8)$ & $47 \%(0.0)$ & Rhode Island & $136 \%(6.8)$ & $50 \%(0.0)$ \\
Indiana & $143 \%(5.3)$ & $47 \%(0.0)$ & South Carolina & $138 \%(4.3)$ & $49 \%(1.4)$ \\
Kansas & $143 \%(5.6)$ & $55 \%(0.0)$ & South Dakota & $155 \%(4.2)$ & $50 \%(0.0)$ \\
Kentucky & $160 \%(7.9)$ & $62 \%(1.6)$ & Tennessee & $142 \%(6.6)$ & $44 \%(2.7)$ \\
Louisiana & $143 \%(6.2)$ & $39 \%(2.2)$ & Texas & $153 \%(4.0)$ & $52 \%(0.0)$ \\
Massachusetts & $135 \%(3.0)$ & $50 \%(0.0)$ & Utah & $151 \%(4.5)$ & $49 \%(0.1)$ \\
Maryland & $144 \%(5.7)$ & $54 \%(0.0)$ & Virginia & $154 \%(3.3)$ & $52 \%(0.0)$ \\
Maine & $161 \%(4.2)$ & $59 \%(0.0)$ & Vermont & $147 \%(5.7)$ & $58 \%(0.0)$ \\
Michigan & $140 \%(3.9)$ & $53 \%(1.5)$ & Washington & $137 \%(2.3)$ & $50 \%(0.0)$ \\
Minnesota & $145 \%(5.7)$ & $50 \%(0.0)$ & Wisconsin & $154 \%(2.5)$ & $52 \%(0.0)$ \\
Missouri & $154 \%(3.7)$ & $51 \%(1.5)$ & West Virginia & $157 \%(3.2)$ & $55 \%(1.3)$ \\
Mississippi & $147 \%(8.9)$ & $41 \%(2.5)$ & Wyoming & $154 \%(6.5)$ & $52 \%(0.0)$ \\
\hline & & & & & \\
& & & & &
\end{tabular}

Notes: this table reports the median statutory replacement rate for April through July 2020 with and without Federal Pandemic Unemployment Compensation (FPUC). The median replacement rates we report exceed measures of mean replacement rates calculated a part of the Department of Labor's Benefit Accuracy Measurement (BAM) program. For example, using the 2019 ASEC to model benefits in 2019Q2, we find that the national median replacement rate is $50 \%$ while the mean "replacement rate 2 " in BAM is $36 \%$. This is because benefits schedules have caps, which lower replacement rates for unemployed with high pre-job loss earnings. These caps bring down mean replacement rates but are not relevant for the median unemployed worker. Many states have a reported standard error of zero for their replacement rate without FPUC. The best way to convey the intuition for how this can arise is to consider a scenario where there is no cap in unemployment benefits, so every worker has the same replacement rate. In this case, regardless of whether the inference procedure is a bootstrap or replicate weights, we will find that there is no sampling-based uncertainty about the median replacement rate. In practice, states with benefit caps that are high relative to the median wage for unemployed workers will have a standard error of zero. 
Figure A-1: Comparison of our calculations to Department of Labor benchmarks

(a) Benefits 2020

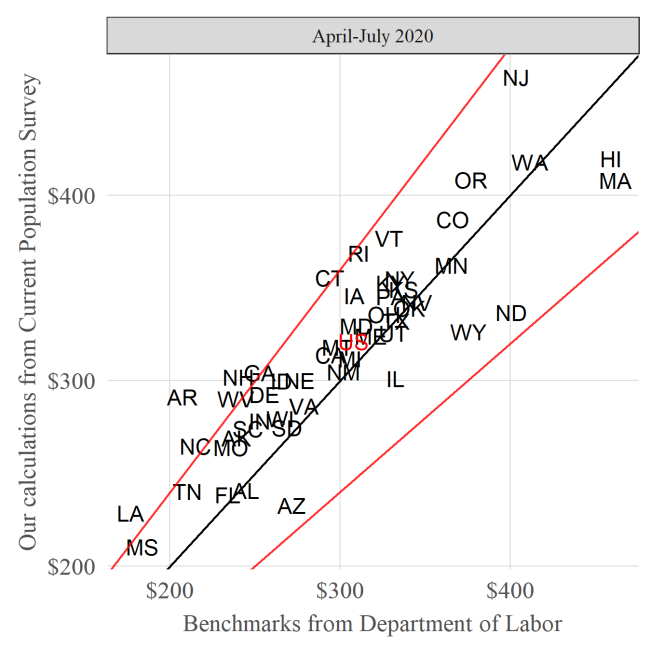

(b) Benefits 2019

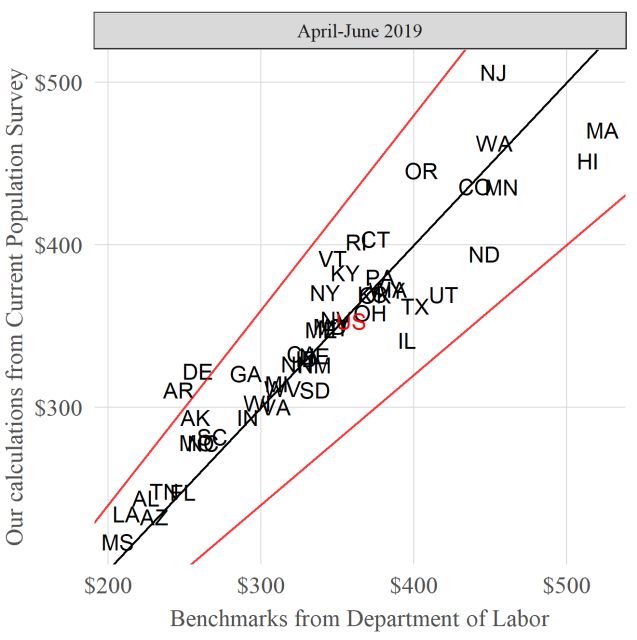

(c) Earnings 2018

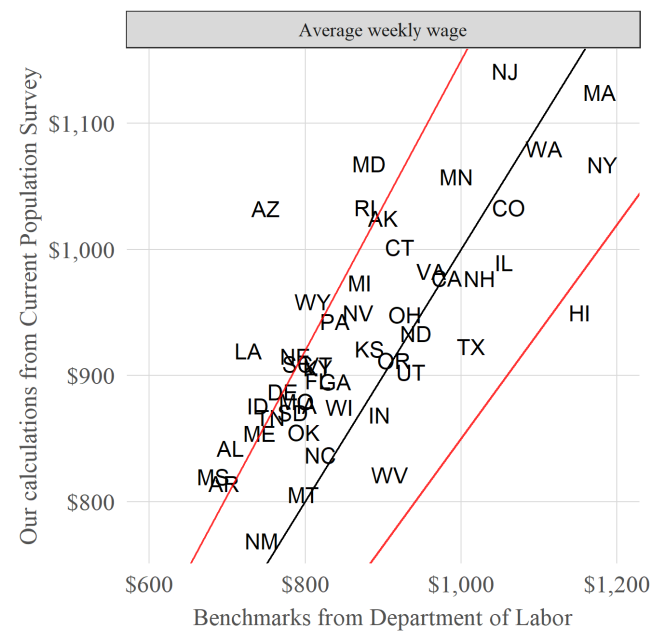

Notes: This figure shows how our estimates of average benefits (pre-CARES) and average pre-job loss earnings among workers eligible for regular Unemployment Compensation compare to administrative data released by the Department of Labor. Panel (a) compares UI benefits to benchmarks from Department of Labor Form 5159 in 2020. Panels (b) and (c) compare our calculations from the 2019 ASEC to external benchmarks. The 2019 ASEC is administered in the spring of 2019 and captures earnings history in calendar year 2018; thus, panel (b) compares average UI benefits in spring 2019 to benchmarks from Form 5159 and panel (c) compares weekly earnings in 2018 to benchmarks from the Benefit Accuracy Measurement data. The black line marks out perfect equality and the two red lines plot a $20 \%$ error. The analysis in panels (b) and (c) predicts each worker's probability of unemployment by estimating equation 1 in the 2019 ASEC (rather than the 2020 basic monthly CPS, which is what we use in our main analysis). 
Figure A-2: Median Statutory Replacement Rates by Industry

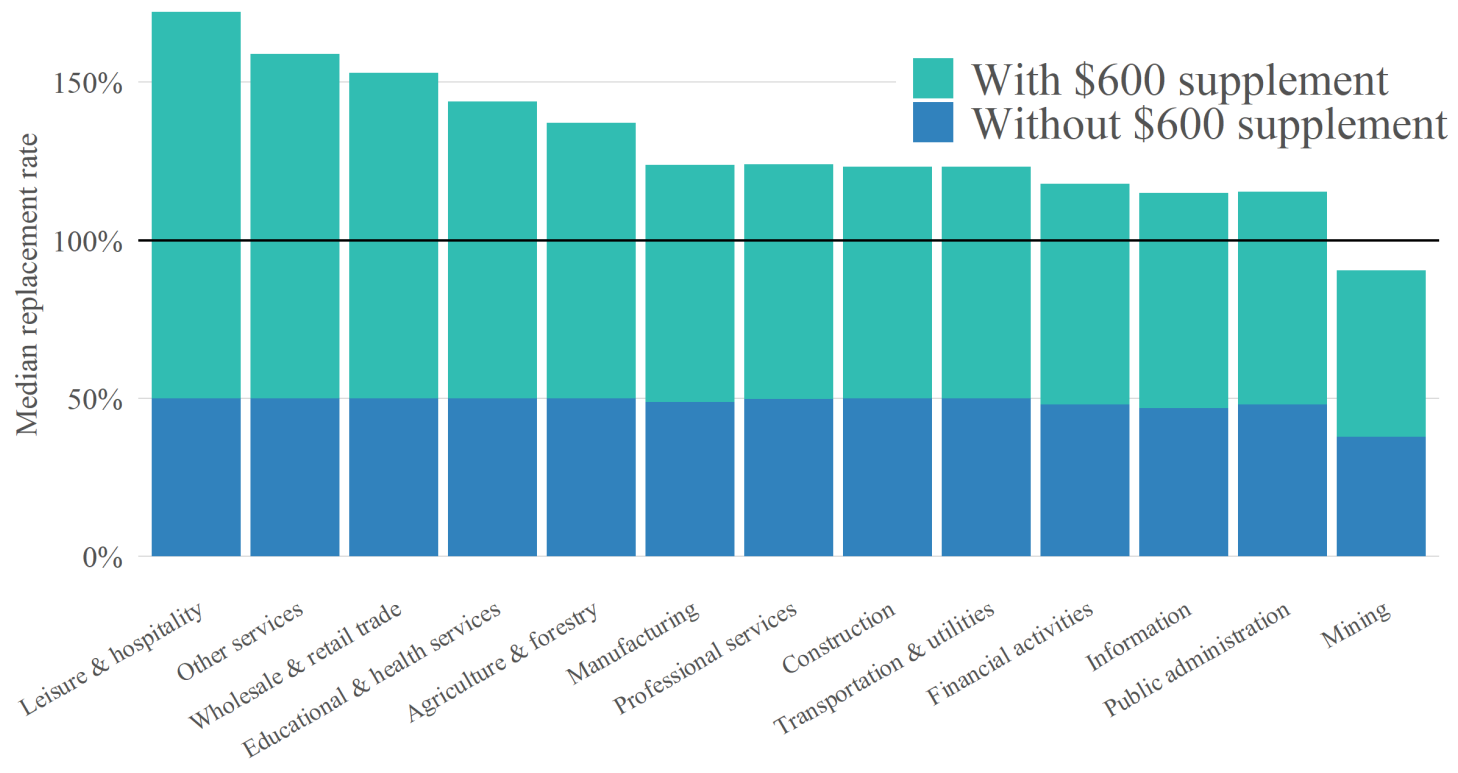

Figure A-3: Median Statutory Replacement Rates by State

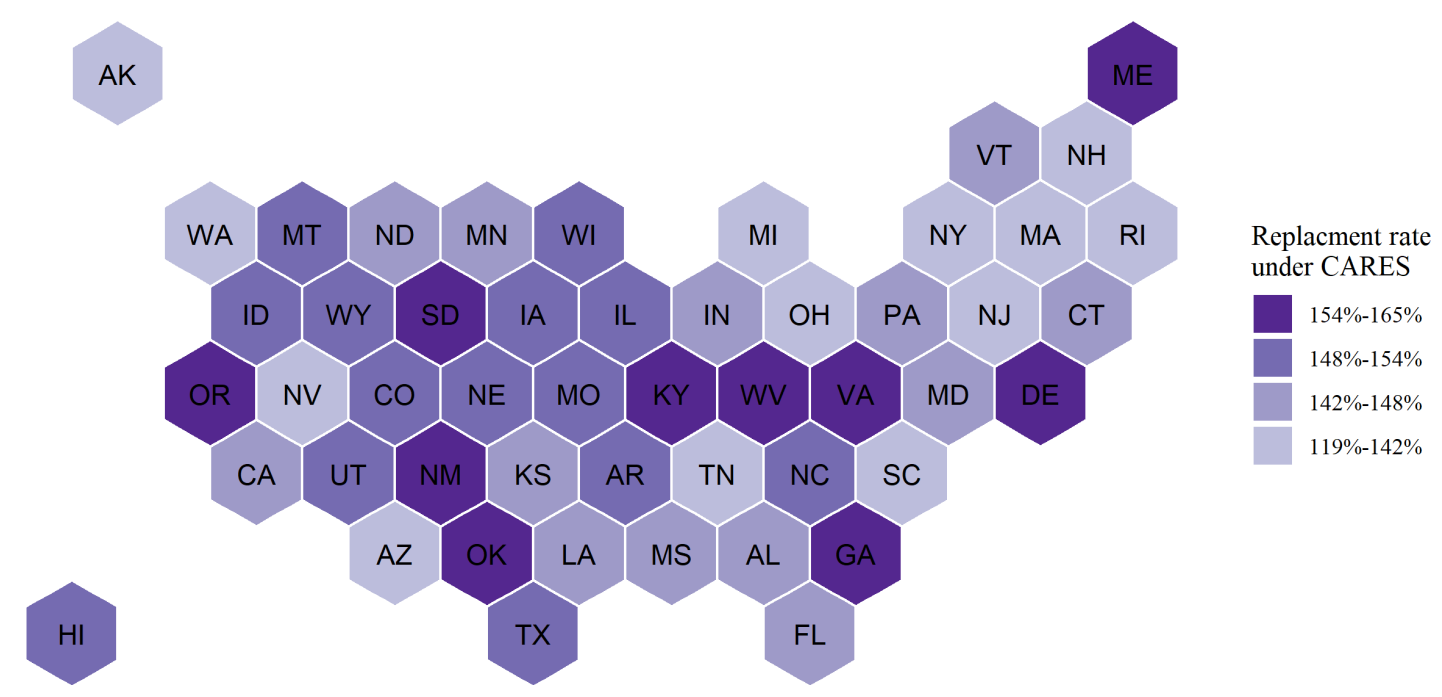

Notes: See notes to Table A-1 for details. 
Figure A-4: Histogram of Replacement Rates for Alternative UI Policies

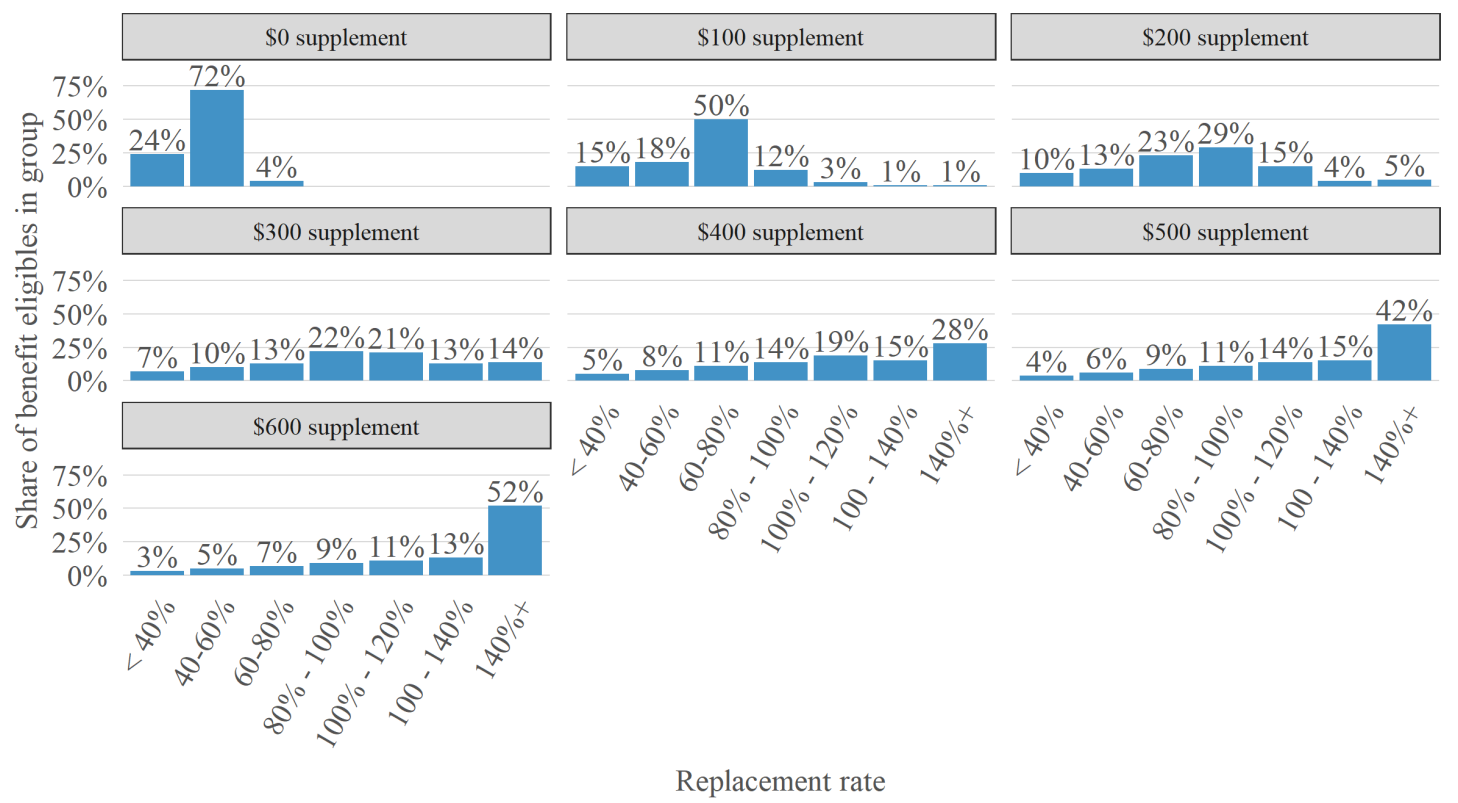

Table A-2: Incidence by Industry

\begin{tabular}{lrrrrrr}
\hline & & \multicolumn{2}{c}{ Unemployment rate } & & \multicolumn{2}{c}{ Median change in income } \\
Industry & Weekly earnings & 2019 & 2020 & & without FPUC & with FPUC \\
\hline Leisure \& hospitality & $\$ 591$ & $5.4 \%$ & $34.4 \%$ & & $-17.5 \%$ & $10.8 \%$ \\
Agriculture \& forestry & $\$ 748$ & $2.7 \%$ & $3.8 \%$ & $-0.1 \%$ & $2.3 \%$ \\
Other services & $\$ 748$ & $2.7 \%$ & $17.4 \%$ & $-8.7 \%$ & $2.2 \%$ \\
Wholesale \& retail trade & $\$ 748$ & $4.3 \%$ & $14.3 \%$ & $-5.4 \%$ & $3.6 \%$ \\
Educational \& health services & $\$ 906$ & $2.2 \%$ & $9.9 \%$ & $-4.6 \%$ & $0.4 \%$ \\
Construction & $\$ 984$ & $3.4 \%$ & $11.1 \%$ & $-4.5 \%$ & $0.7 \%$ \\
Transportation \& utilities & $\$ 984$ & $3.8 \%$ & $12.3 \%$ & $-5.0 \%$ & $0.8 \%$ \\
Manufacturing & $\$ 1,024$ & $2.3 \%$ & $11.3 \%$ & $-5.8 \%$ & $-0.8 \%$ \\
Financial activities & $\$ 1,140$ & $1.6 \%$ & $5.8 \%$ & $-2.7 \%$ & $-0.3 \%$ \\
Information & $\$ 1,181$ & $3.1 \%$ & $12.4 \%$ & $-6.2 \%$ & $-1.2 \%$ \\
Professional services & $\$ 1,181$ & $3.1 \%$ & $8.7 \%$ & $-3.5 \%$ & $0.0 \%$ \\
Public administration & $\$ 1,181$ & $1.9 \%$ & $3.3 \%$ & $-0.7 \%$ & $0.6 \%$ \\
Mining & $\$ 1,477$ & $5.1 \%$ & $6.9 \%$ & $-0.7 \%$ & $1.6 \%$ \\
\hline
\end{tabular}

This table replicates Table 1 panel (b), except uses industry rather than occupation as the unit of grouping. See notes to Table 1 for details. 